\title{
Principal Component Analysis for Identification of Superior Castor Bean Hybrids
}

\author{
Gabriela N. da Piedade ${ }^{1}$, Lucas V. Vieira ${ }^{1}$, Amanda R. P. dos Santos ${ }^{1}$, Deoclecio J. Amorim ${ }^{1}$, \\ Maurício D. Zanotto ${ }^{1} \&$ Maria M. P. Sartori ${ }^{1}$ \\ ${ }^{1}$ School of Agriculture, São Paulo State University, Botucatu, Brazil \\ Correspondence: Gabriela N. da Piedade, School of Agriculture, São Paulo State University (UNESP), Avenida \\ Universitária 3780, Botucatu, Brazil. Tel: 55-149-9800-7243. E-mail: gabriela.piedade@unesp.br
}

Received: March 21, 2019

doi:10.5539/jas.v11n9p179
Accepted: April 27, $2019 \quad$ Online Published: June 30, 2019

URL: https://doi.org/10.5539/jas.v11n9p179

\begin{abstract}
The identification of superior genotypes in plant breeding programs is not a quick and simple task and requires breeders to become aware of more suitable and efficient tools for evaluating crop performance. Univariate analyses are often too narrow for the scope of plant breeding because it lacks consideration of relations between variables. Therefore, the objective of this study was to select castor bean hybrids based on principal component analysis (PCA). Trials were conducted in 2017 with 31 hybrids in a randomized block design with 4 replications. The following variables were used to evaluate crop performance: plant height $(\mathrm{PH})$, insertion height of the primary raceme (HPR), number of stem nodes (NN), number of racemes (NR), number of seeds (NS), stem diameter (SD), number of fruits (NF), 100-seed weight (S100) and seed oil content (SOC). The first three principal components (PCs) explained approximately $75.01 \%$ of all the variability in the dataset. PC 1, 2 and 3 were particularly related to productivity (NS, NR, S100 and NF), plant size (SD, HPR and PH) and oil production (SOC), respectively. Hybrids 14 and 23 were the most suitable for grain production in commercial scale due to short-height, which favors mechanical harvesting. Commercial hybrid 26 showed high SOC, medium grain yield and medium-height.
\end{abstract}

Keywords: biplot, genotype selection, multivariate analysis, Ricinus communis $\mathrm{L}$.

\section{Introduction}

Castor bean (Ricinus communis L.) is a tropical plant with high tolerance to drought and high-temperatures. It is cultivated in Northeastern Brazil, where it plays an important economic and social role, particularly due to its oil production potential (Costa, Beltrão, Silva, Melo Filho, \& Silva, 2010).

Castor oil is obtained by pressing its seeds, which is used in the manufacturing of several products such as soaps, lubricants, hydraulic and brake fluids, dyes, and pharmaceuticals (Scholz \& Silva, 2008). Oil content varies between 48 and $60 \%$ and is comprised of 80 to $90 \%$ ricinoleic acid, a monounsaturated, 18-carbon fatty acid with a hydroxyl functional group on the $12^{\text {th }}$ carbon, which makes it more polar than most fats (Beltrão, Vale, \& Silva, 2008).

There has been increasing interest in castor oil production due to its market value. As a result, cultivation has expanded to different regions in the country creating the need for the development of cultivars more adapted to a wide range of environmental condition, which allows farmers to better exploit the crop commercially (Costa et al., 2006).

However, the identification of superior genotypes in a breeding program is not a quick and simple task, and breeders should be aware of more suitable and efficient methods for evaluating crop performance. Genotype-based selection studies are traditionally described through univariate statistical analyses. Nevertheless, such approach may compromise interpretations and conclusions by not exploiting the dependence among variables. Moreover, selection based on one or a few traits often leads to failure since univariate approach is often too narrow for the scope of plant breeding (Fikdalski, Tormena, \& Scapim, 2007). Breeding a crop for a particular trait involves a complex system of several interacting factors which give rise to several variables which may or not be of interest for breeding.

On the other hand, multivariate analysis allows researchers to obtain more information from a data set by considering not only each variable by itself but also the relation among them (Grobe, 2005). According to Beebe, 
Pell, and Seasholt (1998), multivariate techniques are a key tool in plant breeding programs as it increases selection efficiency. Among these techniques, principal components analysis (PCA) aims at reducing the set of traits and thus simplifying structurally the data set so that differences between treatments, in principle influenced by a larger set of traits, can be evaluated in two- or three-dimensional spaces of easy geometric interpretation (Cruz, Regazzi, \& Carneiro, 2012). The technique creates orthogonal axes called principal components (PCs), which are linear combinations of the original variables (Leite et al., 2016).

Multivariate techniques have been applied to evaluate the performance of several crops including corn, rice, and beans. For instance, Oliveira, Gravina, and Oliveira (2018) applied multivariate analysis techniques (PCA and UPGMA) as a tool for selecting bean genotypes with desirable agronomic traits. PCA has also been applied to studies involving phenotypic divergence in corn genotypes (Greveniotis, Bouloumpasi, Tsakiris, Sioki, \& Ipsilandis, 2018), to identify superior accessions of rice when subjected to below-optimum temperatures during the initial development phase (Moura et al., 2018), and to identify and group different soybean cultivars (Panero et al., 2018).

Despite the importance of such a tool, application of multivariate methods in castor breeding programs are lacking. One of the few studies which address the topic was Sartori, Silva, and Zanotto (2018), who investigated the efficiency of multivariate methods such as clustering methods (complete link, Euclidian distance and the nearest neighbor method) and PCA to select short-height, high-yielding castor bean cultivars. While dendrograms in clustering methods yielded contrasting results, PCA allowed to efficiently select genotypes based on all desired traits concomitantly. Therefore, the objective of this study was to evaluate PCA as a tool to select castor bean hybrids.

\section{Materials and Methods}

\subsection{Characterization of the Experimental Area}

The experiment was carried out at Bariri-SP $\left(22^{\circ} 4^{\prime} 28^{\prime \prime} \mathrm{S}\right.$ and $\left.48^{\circ} 44^{\prime} 26^{\prime \prime} \mathrm{W}\right)$ at $440 \mathrm{~m}$ meter above sea level. According to Köppen Climate Classification, trials were conducted in a tropical zone with dry winter (Aw) (Alvares, Stape, Sentelhas, Gonçalves, \& Sparovek, 2013).

\subsection{Material Studied and Management of the Experiment}

31 hybrids of castor bean were evaluated, 28 were developed by the breeding program from the School of Agriculture at São Paulo State University (UNESP), and 3 commercial hybrids were used as controls: Sara (hybrid 26) and Lyra (hybrid 27 and 28). The evaluation was performed on December 9, 2017 at harvest.

Two days prior to planting, seeds were treated with were carboxinthiran fungicide (Vitavax-thiran-300 ml product $/ 100 \mathrm{~kg}$ seed) and thiametoxan insecticide (Cruiser-300 g product $/ 100 \mathrm{~kg}$ seed).

\subsection{Experimental Planning and Variables}

The experiment design was a randomized complete block with 4 replicates. Each experimental plot consisted of a 2.5-meter line, with spacing of 1.0-meter between rows and 0.5 -meter between plants, a total of $2.5 \mathrm{~m}^{2}$ of useful plot, with no border line between them. Planting was done manually, using three seeds per pit, and then, after thinning, one plant was kept in each pit. Fertilization and crop management were carried out according to the technical indications for Castor bean cultivation in São Paulo (Savy Filho, 2005).

After the complete development of the plants, the following parameters were evaluated:

a) Plant Height $(\mathrm{PH})$ : measurement of all plants of the plot, from the soil surface to the apex of the highest racemus, in centimeters;

b) Insertion Height of the Primary Raceme (HPR): measure from the soil surface until the insertion of the primary racemes, at the time of maturation of the last racemes, in centimeters;

c) Number of Stem Nodes (NN): counting the number of nodes from the soil to the region of insertion of the primary raceme, of all the plants in the plot;

d) Number of Racemes (NR): average number of racemes per plot;

e) Number of Seeds (NS): average number of seeds per plot;

(f) Stem Diameter (SD): measure the diameter at the middle third of the stem with the aid of a caliper in centimeters;

g) Number of Fruits (NF): average number of fruits per plot;

(h) 100-Seed Weight (S100): mass of 100 seeds taken at random from the plots; 
i) Seed Oil Content (SOC): percentage of oil according to Soxhlet methodology (Silva \& Queiroz, 2002).

\subsection{Statistical Analyzes}

Data was subjected to principal component analysis (PCA) to reduce the number of variables in the original data set to a more significant set of variables, while maintaining maximum information. Since the original variables do not have the same unit, the correlation matrix was used as a way of prior standardization of the data (centering on the mean and reducing to the unit of standard deviation). If standardization is not, variables having higher variances would be emphasized in the first components (Wilks, 2006).

Eigenvectors, which are coefficients associated positively or negatively with each original variable, were compared to identify how much each PC was explained by each variable and to define those that contributed the most to the formation of each selected PCs. Scores, which are assumed values of each PC for the studied hybrids, are then obtained from the eigenvectors. Finally, such information allows the identification of those hybrids that best stood out in relation to each PC.

In order to graphically represent our results and verify the correlations between the variables, PCA biplots were built using eigenvectors and scores data in two-dimensional form (Gabriel, 1971). Variables that have vectors with angle smaller than $90^{\circ}$ are positively correlated, greater than $90^{\circ}$ are negatively correlated, and equal to 0 display no correlation (Yan \& Fregeau-Reid, 2008). Data analysis was performed using software R 3.5.2.

\section{Results and Discussion}

Mean annual temperature at Bariri was $22.5^{\circ} \mathrm{C}$, while precipitation varied between 1100 and $1700 \mathrm{~mm}$. Beltrão, Azevedo, Lima, and Queiroz (2007) reported ideal temperature required by castor bean for growth and development varies from 20 to $30^{\circ} \mathrm{C}$ with an optimum around $23{ }^{\circ} \mathrm{C}$, while annual precipitation level is between 650 and $800 \mathrm{~mm}$ with an optimum between 700 and $1400 \mathrm{~mm}$. Thus, the experiment was carried out with ideal conditions the crop.

The amount of variance explained by PCs is key to define the number of PCs to be kept. For Rencher (2002), the proportion of variance explained by PCs should correspond to at least $70 \%$. In our results, the first three PCs explained approximately $75.01 \%$ of all the variability in the data set $(40.92 \%$ explained by PC1, $22.11 \%$ by PC2 and $11.98 \%$ by PC3) (Table 1). According to Cruz et al. (2012), such process makes statistical calculations and interpretation simpler than other methods.

Table 1. Principal components, eigenvalues, proportion of explained variance and cumulative proportions

\begin{tabular}{llll}
\hline Principal Components & Eigenvalues $(\lambda)$ & Proportion & Cumulative Proportion \\
\hline PC1 & 1.9190 & 0.4092 & 0.4092 \\
PC2 & 1.4107 & 0.2211 & 0.6303 \\
PC3 & 1.0383 & 0.1198 & 0.7501 \\
PC4 & 0.9692 & 0.1044 & 0.8545 \\
PC5 & 0.7334 & 0.0607 & 0.9142 \\
PC6 & 0.5756 & 0.0368 & 0.9510 \\
PC7 & 0.5533 & 0.0341 & 0.9851 \\
PC8 & 0.3331 & 0.0123 & 0.9974 \\
PC9 & 0.1520 & 0.0026 & 1.0000 \\
\hline
\end{tabular}

Other strategy to select PCs is called Kaiser (1958) criterion, which determines that the number of components must be equal to the number of eigenvalues ( $\mathrm{PC}$ variances) with mean greater than or equal to the variances of each variable in the original data set. PCA was performed on the correlation matrix with standard variables. This criterion considers that PCs with eigenvalues $>1(\lambda i>1)$ are enough to represent the total variability present in the original data set.

By ordering eigenvalues from highest to lowest using the scree plot, it is possible to define the number of PCs that should be considered for analysis $(\lambda i>1)$ through the slope of the curve. This method also indicated that the first three PCs are enough to study the original data set (Figure 1).

Eigenvectors are key to identify variables that contributed most to each component. $\mathrm{PC} 1$ displayed greater positive associations with the following variables: NS, NR, S100 and NF. For PC2, such positive associations were also observed for the following variables: SD, HPR and PH. However, tall-height, thick-stem plants are commercially 
unsuitable since it makes difficult for mechanical harvesting (Lopes, Beltrão, Lopes Neto, \& Pedroza, 2008; Ferreira, Maruyama, \& Soratto, 2009). In addition, HPR is a characteristic related to precocity. Late-maturity cultivars launches the first raceme at higher height compare to early-maturity ones (Severino et al., 2006), which can be unfavorable to production systems. Conversely, there was a strong negative association between SOC and PC3 (Table 2).

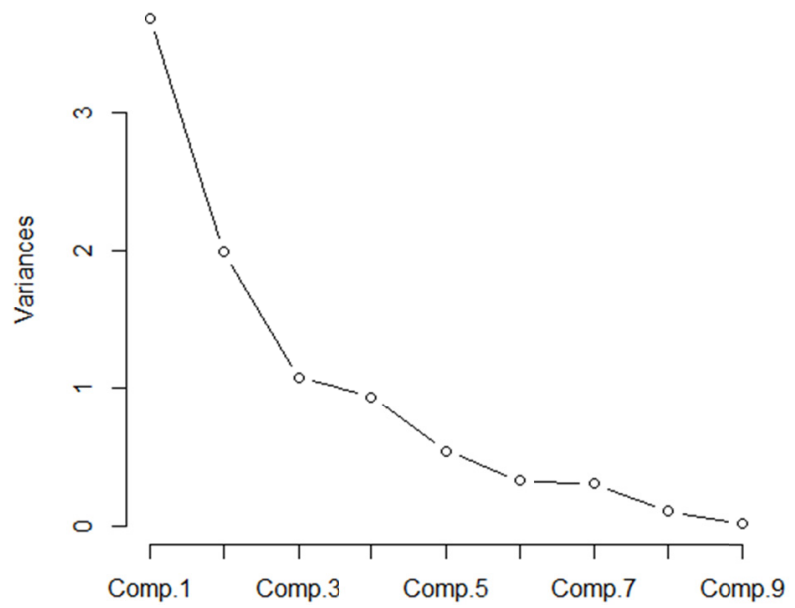

Figure 1. Scree plot of eigenvalues (variances of principal components)

Table 2. Eigenvectors of the number of racemes (NR), number of fruit (NF), number of seed (NS), number of stem nodes (NN), height of the primary racemes (HPR), plant height (PH), stem diameter (SD), seed oil content (SOC) and 100-seed weight (S100), the three principal components (PC1, PC2 and PC3)

\begin{tabular}{llll}
\hline Variáveis & PC1 & PC2 & PC3 \\
\hline NR & 0.4723 & -0.0542 & 0.1424 \\
NF & 0.4382 & 0.0071 & -0.2522 \\
NS & 0.4728 & 0.0710 & -0.1464 \\
NN & -0.2872 & 0.3518 & -0.4393 \\
HPR & -0.0190 & 0.5246 & -0.5046 \\
PH & 0.1723 & 0.4896 & 0.3853 \\
SD & -0.0375 & 0.5513 & 0.3162 \\
SOC & 0.1719 & -0.1718 & -0.4457 \\
S100 & 0.4668 & 0.1411 & -0.0026 \\
\hline
\end{tabular}

Therefore, PC1, 2 and 3 are particularly related to productivity, plant size and oil production, respectively, which are important traits to select high performance genotypes. Goodarzi, Darvishzadeh, Hassani, and Hassanzaeh (2011), studied the genetic diversity of 12 castor bean accessions using 32 variables related to morphological and yield traits. The authors found that the first three CPs expressed $72 \%$ of the total data variability. In addition, SD was positively associated with PC1, while SOC was negatively associated with PC2. These results are in line with our findings.

Score-based selection is facilitated by the classification of previous PCs according to the objective of the breeding program (Table 3). 
Table 3. Scores for hybrids in relation to the three principal components (PC1, PC2 and PC3)

\begin{tabular}{|c|c|c|c|}
\hline \multirow{2}{*}{ Hybrids } & \multicolumn{3}{|c|}{ Principal Components } \\
\hline & $\mathrm{PC} 1$ & PC2 & PC3 \\
\hline 1 & -1.5628 & 1.5698 & -0.0999 \\
\hline 2 & 0.9724 & 0.1679 & -0.2366 \\
\hline 3 & 0.9953 & -0.5492 & 0.2444 \\
\hline 4 & -0.5322 & -0.4541 & -0.2635 \\
\hline 5 & 0.8725 & -1.5546 & -0.1869 \\
\hline 6 & -2.8328 & -0.9213 & 0.1218 \\
\hline 7 & -1.4180 & -1.2245 & -0.1246 \\
\hline 8 & -0.3910 & -0.2140 & 0.0805 \\
\hline 9 & 1.4344 & 0.7384 & 1.1222 \\
\hline 10 & 1.3982 & 0.5639 & 0.1826 \\
\hline 11 & 0.5995 & 2.1935 & 0.7488 \\
\hline 12 & -1.1383 & -2.2651 & -0.1408 \\
\hline 13 & 0.1121 & 1.2808 & 0.2751 \\
\hline 14 & 4.7972 & -0.4887 & 0.7811 \\
\hline 15 & -2.9734 & -1.4110 & -0.1589 \\
\hline 16 & -0.6820 & -1.3314 & -0.5598 \\
\hline 17 & 0.7555 & -0.4813 & 0.0675 \\
\hline 18 & 1.8385 & 2.1191 & 2.3254 \\
\hline 19 & -0.7975 & 1.2632 & 0.8229 \\
\hline 20 & -0.4344 & -0.6040 & 0.4695 \\
\hline 21 & -0.2501 & -1.0996 & 1.5946 \\
\hline 22 & -2.2975 & 1.5422 & 0.6103 \\
\hline 23 & 3.9006 & 0.0303 & -0.3778 \\
\hline 24 & 1.7581 & 0.5268 & -1.7058 \\
\hline 25 & 1.0211 & 0.3183 & 0.4261 \\
\hline 26 & 1.9706 & -0.3249 & -2.6905 \\
\hline 27 & 1.2770 & 1.4260 & -2.6675 \\
\hline 28 & -2.3590 & -0.6839 & 1.0581 \\
\hline 29 & -4.2702 & 3.9196 & -1.3968 \\
\hline 30 & -1.2132 & -2.5917 & -0.5812 \\
\hline 31 & -0.5506 & -1.4505 & 0.2397 \\
\hline
\end{tabular}

In our case, hybrids that displayed high positive scores for PC1 were associated with grain yield, while those that displayed higher negative scores for PC2 and PC3 were associated with plant size and the oil productivity. Therefore, hybrids 14 and 23 could be recommended based on PC1, hybrids 30 and 12 by CP2, and hybrid 24 and commercial hybrids 26 and 27 by PC3 (Table 3 ).

No hybrid displayed superior performance for all three components simultaneously (grain, oil yield and short-height). Biplots combines eigenvectors and scores in a two-dimension structure that allows researchers to identify hybrids with desired traits as well as the correlation among them (Gabriel, 1971).

Variables related to grain yield (NS, NR, S100 and NF) and to plant height (SD, HPR and PH) showed a positive correlation with each other $\left(\alpha<90^{\circ}\right)$, and thus breeders could potentially consider these variables as part of two groups that represent specific traits. However, correlation coefficients between these groups was very low $(\alpha \approx$ $90^{\circ}$ ) or not significant. Hybrids 14 and 23, were the most suitable ones for cultivation for grains (PC1). In addition, these hybrids were more suitable to mechanical harvesting as they displayed shorter height than the average (PC2) (Figure 2). 


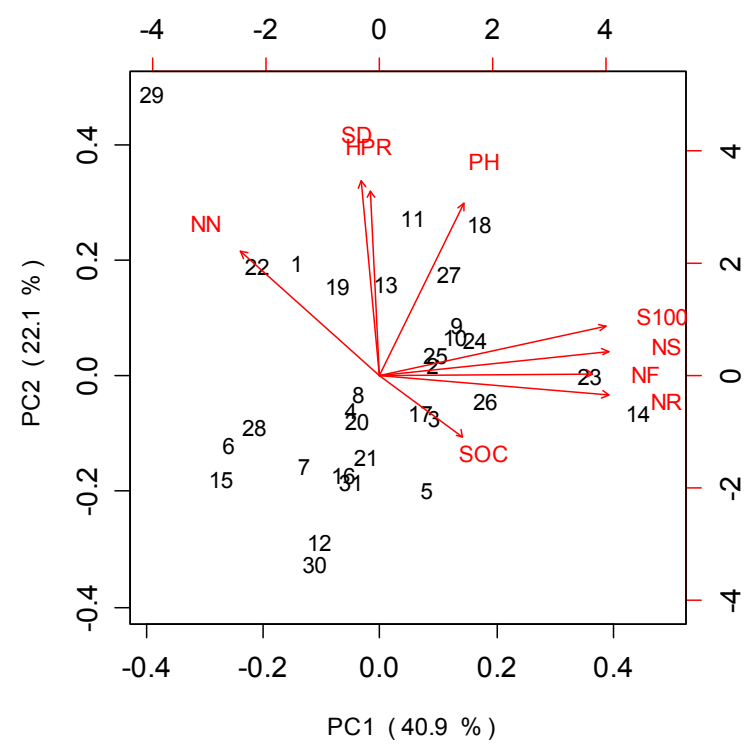

Figure 2. Biplot displaying eigenvectors and scores for principal components 1 and principal components 2

Variables related to grain yield showed a weak positive correlation $\left(\alpha \leq 90^{\circ}\right)$ with SOC. Similar results were found by Souza-Schlick, Soratto, Pasquali, and Fernandes, (2011) while studying castor bean cultivar IAC 2028. This explains why hybrids 26, 27 and 24 had a greater oil production (PC3), which is a characteristic of greater interest in the commercialization of castor bean seeds. However, these hybrids displayed average performance regarding to grain yield (PC1) (Figure 3).

A negative correlation $\left(\alpha>90^{\circ}\right)$ between oil production and variables related to plant height is possibly related to excessive growth that not only causeed problems to harvest but also decreased yield since the energy expenditure for leaves and stem growth competes with seed and oil production (Severino et al., 2006). Only the commercial hybrid 26 was below average (PC2) among the hybrids selected for oil production (PC3), which is favorable for mechanical harvest (Figure 4).

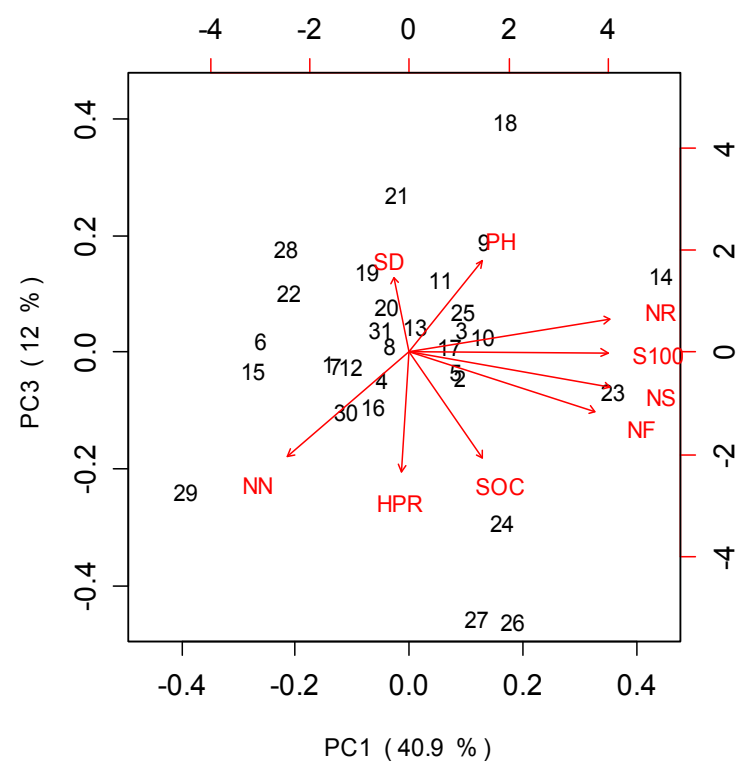

Figure 3. Biplot displaying eigenvectors and scores for principal components 1 and principal components 3 


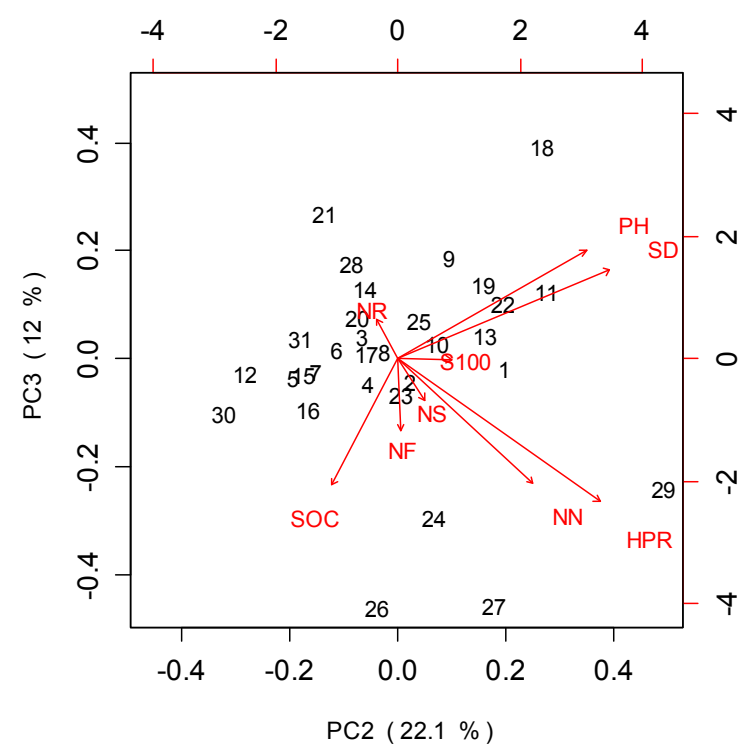

Figure 4. Biplot displaying eigenvectors and scores for principal components 2 and principal components 3

\section{Conclusions}

Hybrids 14 and 23 are the most suitable for grain production in commercial scale as they display short-height, favoring mechanical harvesting. Commercial hybrid 26 showed high oil production, medium grain yield and medium height.

\section{Acknowledgements}

We would like to thank to the Coordenação de Aperfeiçoamento de Pessoal de Nível Superior-Brasil (CAPES)-Finance Code 001 and the São Paulo Research Foundation (FAPESP/2018/14148-3) for the financial support and collaboration.

\section{References}

Alvares, C. A., Stape, J. L., Sentelhas, P. C., Gonçalves, J. L. de M., \& Sparovek, G. (2013). Koppen's climate classification map for Brazil. Meteorologische Zeitschrift, 22(6), 711-728. https://doi.org/10.1127/ 0941-2948/2013/0507

Beebe, K. R., Pell, R. J., \& Seasholt, M. B. (1998). Chemometrics: A practical guide. New York, NY: John Wiley \& Sons.

Beltrão, N. E. de M., Azevedo, D. M. P. de, Lima, R. de L. S., Queiroz, W. N., \& Queiroz W. C. (2007). Ecofisiologia. In D. M. P. de Azevedo, \& N. E. de M. Beltrão (Eds.), O agronegócio da mamona no Brasil (pp. 44-72). Brasília, Distrito Federal: Embrapa Informação Tecnológica.

Beltrão, N. E. de M., Vale, L., \& Silva, O. R. F. da (2008). Agricultura Tropical: Quatro décadas de inovações tecnológicas, institucionais e políticas. Produção e Produtividade agrícola. Grãos oleaginosos (Vol. 1, pp. 753-766). Brasília, Distrito Federal: Embrapa Informação Tecnológica.

Costa, F. X., Beltrão, N. E. de M., Silva, F. E. A., Melo Filho, J. S., \& Silva. M. A. (2010). Disponibilidade de nutrientes no solo em função de doses de matéria orgânica no plantio da mamona. Revista Verde de Agroecologia e Desenvolvimento Sustentável, 5(3), 204-212.

Costa, M. N. da, Pereira, W. E., Bruno, R. de L. A., Freire, E. C., Nóbrega, M. B. de M., Milani, M., \& Oliveira, A. P. de (2006). Divergência genética entre acessos e cultivares de mamoneira por meio de estatística multivariada. Pesquisa Agropecuária Brasileira, 41(11), 1617-1622. https://doi.org/10.1590/S0100-204X2 006001100007

Cruz, C. D., Regazzi, A. J., \& Carneiro, P. C. S. (2012). Modelos Biométricos Aplicados ao Melhoramento Genético. Editora UFV, Viçosa, Brazil. 
Ferreira, M. G. C., Maruyama, W. I., \& Soratto, R. P. (2009). Avaliação de cultivares de mamona em dois arranjos de plantas no outono-inverno em Cassilândia-MS. Revista Brasileira de Oleaginosas e Fibrosas, $13(2), 53-60$.

Fidalski, J., Tormena, C. A., \& Scapim, C. A. (2007) Espacialização vertical e horizontal dos indicadores de qualidade para um latossolo vermelho cultivado com citros. Revista Brasileira de Ciência do Solo, 31(1), 9-19. https://doi.org/10.1590/S0100-06832007000100002

Gabriel, K. R. (1971). The biplot graphic display of matrices with application to principal component analysis. Biometrika, 58(3), 453-467. https://doi.org/10.1093/biomet/58.3.453

Greveniotis, V., Bouloumpasi, E., Tsakiris, I., Sioki, E., \& Ipsilandis, C. (2018). Evaluation of Elite Open-Pollinated Maize Lines in Two Contrasting Environments. Journal of Agricultural Science, 10(1), 85-101. https://doi.org/10.5539/jas.v10n1p85

Grobe, J. R. (2005). Aplicações da estatística multivariada na análise de resultados em experimentos com solos e animais (Master's thesis, Universidade Federal do Paraná, Curitiba).

Goodarzi, F., Darvishzadeh, R., Hassani, A., \& Hassanzaeh, A. (2011). Study on genetic variation in Iranian castor bean (Ricinus communis L.) accessions using multivariate statistical techniques. Journal of Medicinal Plants Research, 5(21), 5254-5261.

Kaiser, H. F. (1958). The varimax criterion for analytic rotation in fator analysis. Psychometrika, 23(3), $187-200$. https://doi.org/10.1007/BF02289233

Leite W. S., Pavan B. E., Alcântara Neto F., Matos Filho C. H. A., Feitosa F. S., \& Oliveira C. B. (2016). Multivariate exploratory approach and influence of six agronomic traits on soybean genotypes selection. Nativa, 4, 206-210. https://doi.org/10.14583/2318-7670.v04n04a04

Lopes, F. F. de M., Beltrão, N. E. de M., Lopes Neto, J. P., \& Pedroza, J. P. (2008). Crescimento inicial de genótipos de mamoneira com sementes submetidas ao envelhecimento acelerado. Revista Brasileira de Oleaginosas e Fibrosas, 12(2), 69-79.

Moura, D. S., Brito, G. G., Moraes, Í. L., Fagundes, P. R. R., Castro, A. P., \& Deuner, S. (2018). Cold Tolerance in Rice Plants: Phenotyping Procedures for Physiological Breeding. Journal of Agricultural Science, 10(1), 313-324. https://doi.org/10.5539/jas.v10n1p313

Oliveira, T. R. A. de, Gravina, G. de A., Oliveira, G. H. F. de, Araujo, L. C. de, Araújo, K. C., Cruz, D. P. da, Amaral Junior, A. T. do, ... Daher, R. F. (2018). Multivariate analysis used as a tool to select snap bean (Phaseolus vulgaris L.) genotypes. Australian Journal of Crop Science, 12(01), 67-73. https://doi.org/ 10.21475/ajcs.18.12.01.pne661

Panero, J. S., Silva, H. E. B. da, Panero, P. S., Smiderle, O. J., Panero, F. S., Faria, F. S. E. D. V., \& Rodriguez, A. F. R. (2018). Separation of Cultivars of Soybeans by Chemometric Methods Using Near Infrared Spectroscopy. Journal of Agricultural Science, 10(4), 351-360. https://doi.org/10.5539/jas.v10n4p351

R Core Team. (2018). R: A language and environment for statistical computing. R Foundation for Statistical Computing, Vienna, Austria.

Rencher, A. C., \& Christensen, W. F. (2002). Methods of Multivariate Analysis. John Wiley \& Sons, Inc.: Toronto, ON, Canada. https://doi.org/10.1002/0471271357

Sartori, M. M. P., Silva, J. da, \& Zanotto, M. D. (2018). Comparison of methods for selection of castor beans lineages. Comunicata Scientiae, 9(4), 687-694.

Savy Filho, A. (2005). Mamona: Tecnologia Agrícola (p. 105). Campinas, São Paulo: EMOPI.

Scholz, V., \& Silva, J. N. da. (2008). Prospects and risks of the rise of castor oil as a fuel. Biomass and Bioenergy, 32, 95-100. https://doi.org/10.1016/j.biombioe.2007.08.004

Severino, L. S., Ferreira, G. B., Moraes, C. R. de A., Gondim, T. M. de S., Freire, W. S. de A., Castro, D. A. de, ... Beltrão, N. E. de M. (2006). Crescimento e produtividade da mamoneira adubada com macronutrientes e micronutrientes. Pesquisa Agropecuária Brasileira, 41(4), 563-568. https://doi.org/10.1590/S0100-204X 2006000400003

Silva, D. J., \& Queiróz, A. C. (2002). Análise de alimentos métodos químicos e biológicos (3rd ed., p. 235). Viçosa, MG: UFV. 
Souza-Schlick, G. D. de, Soratto, R. P., Pasquali, C. B., \& Fernandes, A. M. (2010). Desempenho da mamoneira IAC 2028 em função do espaçamento entre fileiras e população de plantas na safrinha. Bragantia, 70(3), 519-528.

Wilks, D. S. (2006). Statistical methods in the atmospheric sciences (2nd ed., p. 649). San Diego: Elsevier.

Yan W., \& Fregeau-Reid, J. A. (2008). Breeding line selection based on multiple traits. Crop Science, 48(2), 417-423. https://doi.org/10.2135/cropsci2007.05.0254

\section{Copyrights}

Copyright for this article is retained by the author(s), with first publication rights granted to the journal.

This is an open-access article distributed under the terms and conditions of the Creative Commons Attribution license (http://creativecommons.org/licenses/by/4.0/). 